\title{
Current Situation and Reflection on the Development of Sports Broker Major in Universities
}

\author{
Dong Xiang-rong ${ }^{1,}$, Zhang Qiang $^{1, b^{*}}$ \\ ${ }^{1}$ Department of Physical Education, Shandong Technology and Business University, Yantai, Shandong, P. R. China \\ a985341571@qq.com \\ $b^{*}$ zhangqiang1963cn@163.com
}

\begin{abstract}
With the development of sports industry in China, sports brokers, as a kind of professional talents, are recognized and valued by the public. At present, there are still many deficiencies in the research on the establishment of sports broker major and training approaches of sports broker talents in universities in our country, so the relevant universities should cultivate talents for the development of sports industry through establishing sports broker major, and also provide guarantee for the healthy development of it through bettering the major establishment. The thesis will reflect on the current situation of the sports broker major in universities through exploration and analysis, with the hope to provide help for the industry.
\end{abstract}

Keywords: universities, sports broker major, current situation of development

\section{高校体育经纪人专业的发展现状及思考}

董向荣 ${ }^{1, a}$ 张强 $^{1, b *}$

${ }^{1}$ 山东工商学院体育教学部, 烟台, 山东, 中国

a985341571@qq.com

$b^{*}$ zhangqiang1963cn@163.com

\section{摘要}

随着我国体育产业的发展, 体育经纪人作为一种专业人才, 受到社会大众的认可与重视。目前, 我国 高校对于体育经纪专业设置的研究、体育经纪人才的培养方式还存在许多不足, 所以相关高校通过设 置体育经纪人专业, 为体育产业发展培养人才, 并通过探索进一步完善专业设置, 为体育产业的健康 发展提供保障。文章将通过探讨分析的方式对于高校体育经纪人专业的发展现状做出思考, 希望可以 助力行业发展。

关键词：高校，体育经纪人专业，发展现状

\section{1. 前言}

高校人才培养中，体育经纪人专业是其中一项重 要的专业类型, 通过专业教育, 可以培养出专门从事 体育赛事、体育组织、体育品牌包装、体育活动策划等 方面的人才，为体育事业的发展提供助力。但在高校 体育经纪人专业教学中还存在许多问题, 影响到高校 体育经纪人专业教学工作的效率, 也降低了人才培养 工作的质量。基于此, 需要对其中的问题做出系统性 分析与探讨, 针对其中问题提出相应的改善策略, 从 而助力高校体育经纪人专业教学工作的开展。

\section{2. 高校体育经纪人专业介绍}

高校体育经纪人专业主要以培养体育经纪人为主, 从而为体育提供更多的专业人才储备, 确保体育展现 出良好的发展效率。所谓体育经纪人, 指的主要就是 从事体育赛事、体育组织、体育品牌营销、体育经营策 划等方面的人才, 通过该方面人才的贡献, 可以让体 育事业实现高效的发展, 并且以体育事业带动社会经 济发展，为社会主义经济建设工作的全面发展提供助 力。对于体育经纪人专业来说, 所培养的人才需要充 分符合《体育经纪人国家职业标准》的要求, 并且能够 以良好的职业素养与严格的职业精神，投入到体育事 业当中，为体育事业的发展做出贡献。 


\section{3. 高校体育经纪人培养的重要性}

\section{1 符合体育事业的发展需要}

随着人民生活水平的不断提高，以及国家社会发展持 续向前推进，体育事业开始逐渐产生并且发展了起来， 充分满足了人们日益增长的精神文化需要。所以需要 优质开展体育事业, 从而使体育事业能够更加迎合人 们的欣赏需要。而体育事业在发展的过程中，具有竞 技性与观赏性, 这也是体育事业得到全面发展的重要 原因之一。而在体育事业蓬勃发展的背景下，便需要 拥有更多数量的体育经纪人参与到其中，对于相关体 育赛事进行组织与策划, 从而保证体育赛事能够有条 不紊的开展, 也可以充分保证体育赛事在开展过程中 各个参与方的权益。基于此, 高校体育经纪人专业教 育工作全面发展充分迎合了剧烈的市场需求，不但保 证了高效教育水平, 还为体育事业的优质开展提供了 更为丰厚的人才基础。

\section{2. 保障体育运动竞争的公平性}

在体育产业开展的过程中，其中的竞争性是体育 事业得到市场认可的重要条件之一。同时，为了使体 育事业在发展期间赢得更为广泛的市场, 便需要充分 保障体育竞技的公平性, 然而, 在以往的体育市场中, 由于存在项目垄断、行业垄断等方面现象, 便导致在 体育运动中出现不公平竞争的情况, 而这种情况的出 现，不但限制了体育运动事业的发展，还导致其丧失 大量的体育运动市场资源, 这对于体育运动的发展来 说并无任何裨益。所以, 为了充分保证体育运动市场 在发展与运营过程中的公平性, 促进体育运动之间的 良性竞争, 便需要由体育经纪人参与到其中, 以公平、 公正、客观的态度来规范在体育市场中的各项事务, 这对于促进体育市场良性竞争, 维护体育市场秩序具 有极为重要的意义。

\section{3. 实现体育资源优化配置}

对于体育市场来说体育经纪人在其中占有很重要 的位置, 其还能实现体育资源的优化配置。在市场发 展中, 变化速度快且项目复杂, 同时其中竞争也极为 激烈, 这便导致体育的主体决策中产生不确定因素, 影响到体育市场的规范开展, 很容易出现市场资源分 配不合理的情况, 对于体育事业的高效发展造成了一 定的阻碍 [1]。而通过体育经纪人参与到体育市场资源 分配中, 其能够以科学的手段与严谨的态度, 对于体 育市场的相关信息进行收集、整理、分析, 并且可以通 过市场调研, 掌握体育市场的基本情况, 随后以科学 的手段对体育市场中的资源进行优化配置, 从而有效 降低体育市场在运行过程中的成本消耗, 找到体育市
场商业化发展的有效途径，确保体育市场在发展阶段 充分满足供需双方的利益需求，而通过以上方式便实 现了体育市场资源配置的最优化。

\section{4. 高校体育经纪人专业的发展现状}

\section{1. 缺乏有效的竞争机制}

在高校体育经纪人专业当中，其中最为显著的一 项问题便是缺乏有效的竞争机制，该项问题的出现在 一定程度上影响到高校体育经纪人专业的培养工作中 各项工作无法高效的完成, 降低了人才培养工作的实 效性。不过在体育经纪人专业中，其有可能会受到传 统思维方式的影响, 出现体育经纪人专业管理权力并 未充分实现，受到行政机关的干预与影响，特别是在 大型体育赛事中，其需要依靠政府来对其进行组织与 管理, 而这种情况的产生, 现在体育市场中形成了一 种垄断性的发展模式，这种发展模式对于体育经纪人 专业的发展并没有任何的促进作用，同时，在其中缺 乏合理的竞争机制，便有可能出现其中工作人员工作 态度散漫、工作积极性不高、工作重视程度不足等方 面情况, 在一定程度上影响到体育经纪人专业的发展, 也给高校的体育经纪人专业人才培养工作造成一定影 响。

\section{2. 专业素质偏低}

在高校体育经纪人专业中，还有可能存在的一项 问题就是体育经纪人的专业素质偏低，这便导致人才 培养实效性不足。对于体育经纪人专业来说, 需要掌 握的知识类型较多，例如: 体育经济、体育管理、税务 法律、投资、理财等多方面儿，只有充分且全面的掌握 以上方面知识, 才能保证体育经纪人在实际工作中展 现出良好的工作能力, 并且优质完成本身工作, 此外, 在不同领域的经纪人所需要掌握的知识内容也不尽相 同, 对于体育经纪人的专业要求也具有较大差距。所 以，在人才培养的过程中，往往并不具备针对性，导致 出现体育经纪人专业素质偏低的情况, 这不但影响到 高校体育专业人才培养工作的质量, 导致体育市场缺 乏职业技能较强的专业人才。

\section{3. 培养机制不完善}

高校体育经纪人专业人才培养工作中，培养机制 不完善也是其中一项重要的问题，该问题的存在直接 影响到各项培养工作的开展，也导致在人才培养中出 现实效性不足的情况，而这种情况的产生便限制了高 校体育经纪人专业人才培养工作各个方面工作的开展。 在实际中，通过高校体育经纪人培养可以满足体育市 场对于专业人才的需要，不过在此过程中，主要遵循 
的制度便是《居间人管理办法》，在其中指出，为了有 效提高居间人专业素质, 需要对其开展培训工作。不 过却并未明确说明体育居间人管理制度规范, 在培养 的过程中，仅仅依靠前期的培训制度，并没有后续的 管理与要求, 这种情况的产生便导致体育经纪人在后 续无法受到有效的管理与约束。

\section{4. 体育经纪人管理水平低}

体育经济纪人管理水平较低也是其中一项重要的 问题，对于高校体育经纪人专业发展造成一定程度的 影响, 往往容易出现管理效率低下的问题, 在实际中, 主要表现为容易存在暗箱操作的情况, 甚至在情况严 重的时候还有可能出现体育经纪人从事非法交易活动。 对体育市场的正常竞争秩序造成了严重的影响与破坏 ${ }^{[2]}$ 。此外, 还有可能存在部分体育经纪人滥用职权、以 公谋私等方面现象, 而这些情况的产生, 归根结底就 是由于体育经纪人管理水平较低, 从而导致其中各种 不规范现象频频产生，对于体育事业的发展也造成了 一定程度的影响。

\section{5. 促进高校体育经纪人专业优质发展的建 议性策略}

\section{1. 促进体育经纪人行业良性竞争}

为了全面保证高校体育经纪人专业的高质量发展, 促进体育市场的经济繁荣, 为整个体育经纪市场有条 不紊的运营提供基础条件, 首先要做的一项工作便是 促进体育经纪人行业之间的良性竞争，在人才培养的 过程中, 需要向体育经纪人传达良性竞争的概念, 让 经纪人能够秉承科学、严谨、公平、公正的态度完成自 身的各方面工作, 并且在工作过程中严格遵守体育市 场在发展过程中的各项规则, 在同行业竞争中, 保证 采用良性的竞争手段, 以此在高校体育经纪人专业中 营造出一种充满活力的竞争模式, 这对于高校体育经 纪人专业人才培养工作具有一定程度的促进作用 ${ }^{[3]}$ 。 在实际中, 需要高校在其中投入更多的人力资源, 对 于体育经纪人专业的培养工作付出更多的精力, 积极 总结在以往工作中出现的经验教训, 分析其中问题产 生的因素, 随后制定有效的改善措施, 以此保障体育 经纪人专业能够实现有条不紊的发展, 同时以良性的 竞争模式来提高体育经纪人专业的发展活力。

\section{2. 重点培养体育经纪人专业素质}

还需要对于体育经纪人的专业素质进行重点培养, 提高体育经纪人的专业素养, 令其能够以严格的职业 态度与精神来完成本职岗位上的工作。所以, 高校在
培养体育经纪人的过程中，需要在培养体育经纪人专 业素质方面加大投入力度，采取多元化培养方式来提 高体育经纪人的素质, 从而为体育事业发展提供源源 不断的人才储备，有效促进体育市场经济的繁荣发展 ${ }^{[4]}$ 。在实际中, 可以适当加强在专业素质方面的考核, 对于体育经纪人的专业素质进行检验, 规范其在工作 过程中的各项行为, 从而保证体育经纪人专业实现稳 定且高效的发展。此外, 还需要做到转变传统观念, 遵 循市场发展的规律，以市场需求为导向具有针对性培 养体育经纪人的专业素质, 使体育经纪人能够满足体 育市场发展的需求。

\section{3. 完善体育经纪人培养机制}

完善体育经纪人培养机制也是促进体育经纪人专 业高效发展的有效措施，同时也能使高校体育经纪人 专业展现出巨大的发展潜力。在实际中, 可以成立一 个以体育经纪人为目标的交流沟通平台，所有的体育 经纪人培养机构都可以加入到平台进行交流，探讨培 养措施、分享培养经验等。此外，在交流平台上还可以 搜集到相关体育经纪人的信息，对于信息进行整理， 以此保证体育经纪人专业发展更加具有条理 ${ }^{[5]}$ 。与此 同时，还可以对于当前体育经纪人培养过程中的机制 进行探讨与沟通, 明确在其中所存在的不足, 随后根 据现状，来制定有效的培养措施，从而保证体育经纪 人培养机制得到完善, 为体育行业的高效发展培养出 更多高素质人才。在完善体育经纪人培养机制的过程 中, 需要做到全面且细致，确保全新的人才培养机制 可以涵盖到高校体育经纪人培养工作的各个方面, 从 而保证高校体育经纪人专业更加优质的发展。

\section{4. 提高体育经纪人管理水平}

要充分提升体育经纪人的管理水平，保证体育经 纪人在工作中的各项行为符合规范，不会产生违反职 业道德的情况, 以此为体育提供公平的竞技条件, 从 而确保体育事业获得市场的青睐。在实际管理的过程 中, 需要借助多方力量联合, 不能单单依靠体育部门 的力量, 还需要充分发挥工商部门、税务部门机构的 职能, 共同合作, 实现对于体育经纪人专业的高效管 理，并且提高管理的水平，这对于高校体育经纪人专 业的发展来说具有极大的促进作用 ${ }^{[6]}$ 。与此同时, 在对 于体育经纪人进行管理期间, 还要注意到定期对于体 育人的工作规范性进行审查, 监督其工作中的各项行 为, 一旦发现存在徇私舞弊、假公济私的情况, 便需要 立马对其进行惩罚, 从而达到规范体育经纪人各项行 为的目的。在审查阶段, 要注意采取多方联合审查的 方式, 以保证审查结果的公正性, 从而达到提高体育 经纪人管理工作水平的效果，确保体育经纪人行业实 现井然有序的发展。 


\section{6. 结束语:}

综上所述, 在高校体育经纪人专业人才培养中, 需要付出更多的精力, 并且对于其中所存在的问题做 出细致的分析与探究, 找出问题的成因, 然后制定相 应的措施进行改善, 从而保证高校体育经纪人专业人 才培养工作可以更加优质的完成。文章通过分析阐述 的方式, 对高校体育经纪人专业做出了介绍, 并且探 讨了体育经纪人培养的重要性, 最后依照当前高校体 育经纪人专业人才培养现状提出了有效的改善措施, 希望可以为相关工作人员提供经验参考。

\section{项目基金}

本文为山东工商学院 2019 年财富管理 特色研究项目《基于创新型复合型财富人才 培养的体育经纪人专业建设研究》（项目编 号：2019ZBKY033）的阶段性成果之一。

\section{REFERENCES}

[1] Gai, YD. (2008) Conception of setting up sports broker major in colleges and universities in China. J. Success: Education, 6: 213-214.

[2] Yang, JP. (2009) Research on the feasibility of setting up sports broker major in colleges and universities. J. China Electric Power Education, 3: 112-113.

[3] Cui, XP. (2011) Analysis on the current situation and countermeasures of the development of sports broker in China. J. Journal of Chifeng University, 6: 201-203.

[4] Luo, BQ, Zhang, LM. (2001) On sports broker and its development. J. Journal of Capital University of Physical Education and Sports, 2: 73-76.

[5] Yan, RG. (2008) On the current situation and developmental strategies of sports broker in China. J. Study Monthly, 18: 62-63.

[6] Fang, XY, Ni, G, Wang, HY. (2008) The current situation of legal supervision of sports broker in China and its adjustment countermeasures. J. Sport Science Reseach, 6: 70-73. 